Revista de la red interuniversitaria de estudios sobre las literaturas rioplatenses contemporáneas en Francia

$9 \mid 2013$

Homenaje a Ana María Barrenechea

\title{
Poesía y Traducción : mapa rítmico, partitura y plataforma flotante
}

Delfina Muschietti

OpenEdition

Journals

Edición electrónica

URL: http://journals.openedition.org/lirico/1130

DOI: $10.4000 /$ lirico. 1130

ISSN: 2262-8339

Editor

Réseau interuniversitaire d'étude des littératures contemporaines du Río de la Plata

Referencia electrónica

Delfina Muschietti, «Poesía y Traducción : mapa rítmico, partitura y plataforma flotante », Cuadernos LIRICO [En línea], 9 | 2013, Publicado el 01 septiembre 2013, consultado el 10 diciembre 2020. URL http://journals.openedition.org/lirico/1130 ; DOl : https://doi.org/10.4000/lirico.1130

Este documento fue generado automáticamente el 10 diciembre 2020.

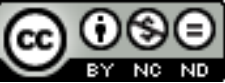

Cuadernos LIRICO está distribuido bajo una Licencia Creative Commons Atribución-NoComercialSinDerivar 4.0 Internacional. 


\title{
Poesía y Traducción : mapa rítmico, partitura y plataforma flotante
}

\author{
Delfina Muschietti
}

\section{Traducir poesía : mapa rítmico, partitura y plataforma flotante}

1 La tarea crítico-estética de traducir poesía nos ha llevado finalmente a una descripción de la especificidad de la forma poética. Mirar y escuchar el poema en otra lengua nos aleja del sentido - devorador, si leemos textos en nuestra lengua primera-; y así, resulta evidente su diseño gráfico y sonoro, su inherente extrañeza, su complejidad formal. Siguiendo a Iuri Tinianov (1923) y a Walter Benjamín (1923), en constelación teórica, podemos decir que, al traducir un poema, perseguimos un fantasma : el "eco" de una respiración, el armado de una construcción rítmica, que hemos llamado mapa rítmico o partitura flotante, y que en esta forma radica la especificad del poema. Podemos concebir el poema como una máquina rítmica, que delega en su motor de repetición una condición anómala o extranjera, que nos lleva a otra dimensión, alejada de la cotidianidad, de los ejes tempo-espaciales que persigue la prosa. Cuando leemos un poema, nos hallamos sumergidos en energías y melodías flotantes, que se entrecruzan y resuenan, y que debemos enfrentar a su vez, con una escucha flotante, término que tomamos de Freud. Sin representación ni personajes sostenidos (hay sí pronombres y nombres, que son sólo nombres¹), la poesía viaja de lo íntimo a lo colectivo, del detalle a lo cultural, en juego de microscópicas y macroscópicas miradas (“Telescopio eyes” dirá Emily Dickinson en el poema J443) sobre la materia de la lengua. En ella, por supuesto, como dicen Adorno y el mismo Tinianov, se halla sedimentada la historia, la sociedad, aún más allá de las intenciones del escriba-poeta, a su vez también escucha, como bien indica Emerson en 1844. Un siglo después, el poeta Williams Carlos Williams coincide:

To make two bold statements: There's nothing sentimental about a machine, and: A poem is a small (or large) machine made out of words. When I say there's nothing sentimental about a poem, I mean that there can be no part that is redundant. 
Prose may carry a load of ill-defined matter like a ship. But poetry is a machine which drives it, pruned to a perfect economy. As in all machines, its movement is intrinsic, undulant, a physical more than a literary character. ${ }^{2}$

2 Los tres adjetivos que usa Williams (intrínseco, ondulante, físico) nos llevan a otro de nuestros teóricos en constelación : Gilles Deleuze. Si el poema es una máquina rítmica, un motor de repetición tanto escriba-poeta como lector se vuelven escuchas (de "oído refinado" especificará Emerson) de esa potencia repetidora, que se arma en mapa, en partitura flotante. ¿De dónde llega ese rumor ondulante y físico? Podríamos pensar con Deleuze (1995) en un "plano de inmanencia" (intrínseco), impersonal y trascendente, esa otra dimensión que provee al poema de materia proyectiva (en términos de otro poeta, Charles Olson 1965) ; y lo regresa partitura, mapa ondulante, en el que la lengua cruza individual y colectivo. De allí la potencia de la gran poesía, que se desmiembra en líneasversos que se independizan, y se constituyen en fuerzas estéticas perdurables, ricas, dinámicas, en transformación y movimiento : fuerzas estéticas y culturales que viven en nuestros oídos y mentes, y que han sido lanzadas desde plataformas flotantes, como se llama a las que disparan los cohetes espaciales. Porque además estas fuerzas viajan veloces, a veces como estrellas fugaces, y son desequilibrantes. El filósofo Alain Badiou (1998) las llama "máquinas de hacer pensar"; siempre y cuando, concluimos, el pensamiento racional cartesiano se abra a otras dimensiones del pensar, que se conectan con la "percepción ampliada", como quería Henry Bergson (1934). Para Badiou en el poema "dicho pensamiento es inseparable de lo sensible, es un pensamiento que no se puede discernir o separar como pensamiento. Digamos que el poema es un pensamiento impensable" (1998 : 64). Inmanencia, inmediatez y velocidad de intuición caracterizan a la poesía.

3 En la poesía de Sylvia Plath la conexión con el plano de inmanencia, o plataforma flotante, se grafica en la posición del cuerpo horizontal, el estar tendido o suspendido (como sucedía con Juanele Ortiz, con Pasolini), que se dispone a la escritura ; mientras la posición del cuerpo vertical refiere al estar atrapado en las redes de la identidad civil y el imaginario cultural, presentado como pre-juicio. Como veremos, Plath piensa la escritura del poema como una tensión para dar forma al caos. Se trata de una forma que, alejándose de la ley del sentido, se liga técnicamente con la materia sonora y el color de las palabras segmentadas en pura materia en el plano de inmanencia, para luego regresar en la composición de la partitura-poema, que va del detalle al infinito :

Every word can be analysed minutely - from the point of view of vowel and consonant shades, values, coolnesses, warmths, assonances and dissonances. Technically, I suppose the visual appearance and sound of words, taken alone, may be much like the mechanics of music ...or the color and texture in a painting. However, uneducated as I am in this field, I can only guess and experiment. (The Journals, "Smith College, 1950-1955", p. 32) ${ }^{3}$

\section{Traduciendo a Sylvia Plath: cuerpo horizontal y cuerpo vertical}

El Ich, Ich que se dice en el famoso poema "Daddy" de 1962 , aparece como el modo de decir Yo en los poemas de Sylvia Plath : es eso lo que señala la mujer que habla : estoy en esa lengua del padre (extranjero y autoritario), que es al mismo tiempo como alambre de púa en donde la lengua propia se atasca ; y también resulta máscara de identidad, cuerpo vertical de la identidad civil al que se renuncia en el poema "Tulips" (1961) a favor del "I 
am nobody" ("Yo no soy nadie") horizontal ${ }^{4}$, que promete un nuevo territorio arcaico libre. El cuerpo propio aparece colonizado y torturado, y encarcelado en la gran mandíbula del otro : ha sido tomado por asalto como los de los judíos enviados por los nazis a los campos de exterminio. Eso parece decirnos el poema. La traducción tiene que respetar ese aliento germánico, extranjero que invade el cuerpo de la lengua nueva. No podemos decir materna, porque, como el diseño de Plath muestra claramente, la lengua de la madre es otra forma de colonización : disciplina austríaca - o sea, la lengua de Plath aparece doblemente sitiada por la lengua germánica ${ }^{5}$ - anclada en la zona rígida de lo americano (el éxito, el dinero, lo puritano, la violencia de las armas ${ }^{6}$ ). La madre recibe dos imágenes reveladoras : es la despiadada luna, con la boca abierta de la desesperación, dibujada en "The yew tree" "The moon is my mother. She is not sweet like Mary": "La luna es mi madre. Ella no es dulce como María.") ; y es la que se identifica con las ranas de sangrefría en "Frog autumn" ("cold-blooded mother" : "madre de sangre-fría"'). De modo que el rasgo de violencia y opresión se pone de diferentes maneras en las dos figuras parentales : del padre, el autoritarismo arrasador y asfixiante; de la madre, la fría disciplina que es casi un desprendimiento de aquél. En ambos, la ausencia del efecto-afecto : ambas figuras parentales son devoradoras en el modo descrito por Mélanie Klein (1957) en Envidia y gratitud, reelaboración del par Eros y Thanatos en Freud. Por eso, en los Diarios, Plath remarca:

Read Freud's Mourning and Melancholia after Ted left to the library. An almost exact description of my feelings and reasons for suicide: a transferred murderous impulse from my mother onto myself: the "vampire" metaphor Freud uses, "draining the ego": this is exactly the feeling I have getting in the way of my writing: Mother's clutch. $(280)^{8}$

5 Y más adelante (entrada del 12 de diciembre de 1958) se llegará a esta precisa y tenebrosa definición, que alcanza el grado rítmico-compositivo de un verso : "she doesn't know she is a walking vampire" ("ella no sabe que es un caminante vampiro"), y se liga con el estatuto del Unheimlich freudiano. La situación de la hija en Plath es la de un aniquilador desamparo o desespero : otra vez refiriéndose a la luna-madre se dice en "The moon and the yew tree" : "With the O-gape of complete despair. I live here" "“Con la O. mueca de la desesperación total. Yo vivo aquí"). Si en "Daddy" la lengua quedaba atrapada en alambres de púa y la hija vivía encerrada en un zapato negro, en "The moon and the yew tree", el habitat-madre es la boca en $O$ que acerca la figura a la del cuadro "El grito" de Munch. No hay salida, entonces, al parecer : "I simply cannot see where there is to get to" ("Yo simplemente no puedo ver a dónde hay que ir"). Sin embargo, en el poema "Little Fugue" (1962) se abrirá la boca del túnel que construye la lengua menor o propia, la luz que llega con la lengua extranjera de la poesía.

6 Volviendo a la tarea de la traducción, ésta tiene que respetar el aliento entrecortado, como nos decía Benjamín. Hablamos, entonces, de una lengua de llegada en cuya respiración se percibe el eco de la lengua de partida. En el caso de Plath, como en la de la mayoría de los poetas contemporáneos- dijimos- , esa lengua de partida ya llega partida. No se habla aquí solamente de las condiciones generales de un yo escindido (el "je est un autre" de Rimbaud), sino también de la práctica de la incrustación de lenguas extranjeras en la homogeneidad de la lengua oficial, o la torsión interna que buscaba Rilke (1985), por ejemplo, para que la lengua "propia" sonara como de otro, extranjera. Se trata siempre de esta extranjería, que César Vallejo buscaba en el arcaísmo, el neologismo, la interferencia de lenguas menores en una lengua mayor. ${ }^{9}$ Tarea del poeta moderno que, una vez más, Rimbaud había señalado con otra de sus precisas frases lacónicas : "Hallar una lengua", o 
cantidad formal propia, decimos con Derrida (1996). Nos preguntamos, entonces, sobre los modos en que el hecho de ser mujer, la cuestión del género, aporta un plus a esa extranjería. Toda una genealogía de poetas "modernas" (desde Emily Dickinson a Plath, desde Alfonsina Storni a Pizarnik) ponen la mira en ese punto : insisten en develar las condiciones particulares en el que un cuerpo de mujer en nuestra cultura debe o puede decir Yo. La poesía de Plath diseña este mapa con maestría : no sólo en el "Ich" del padre autoritario sino también en la despiadada negación del espejo de la madre ; muestra así ciertas condiciones generales ancladas en situaciones extremas particulares. Habrá que salir, entonces, de ese túnel negro hacia la luz que la lengua menor de la poesía ofrece ; y que, paradójicamente, muestra el movimiento que va de la mirada microscópica a la macroscópica, como señalamos al comienzo. De este modo, en "Daddy" la escena privada, psicoanalítica, familiar-edípica, se enfoca en el escenario político de la Gran Guerra (Great War), y así mostrar el cuerpo de esta mujer como un campo de batalla, como un campo de lucha de fuerzas en disputa. ${ }^{10}$ "Daddy" hace juego con "Little Fugue" ("Pequeña fuga"), ambos de 1962. La figura del padre alemán (Otto Plath como fantasma) ${ }^{11}$ le sirve a estos poemas para construir el escenario de una lengua desalojada en un cuerpo-campo de concentración. ${ }^{12}$ Por eso, la lengua de ella, es traqueteada "like a Jew" ("como una judía") en tren camino a "Dachau, Auschwitz, Belsen" : ese recorrido dibuja el poema, ligando la resonancia de esos nombres al poder brutal de los nazis en una secuencia melodiosa a medias entre la repulsa y la atracción, donde resuenan los ecos de una esclavitud de siglos encarnada en el cuerpo de la mujer, cada vez que es sometida a una violencia autoritaria. Aquí y allá resonarán sonidos fuertes ligados a la lengua alemana del padre, entronizado como un jerarca nazi : your Luftwaffe, Aryan eye, Panzer-man, swastika, Meinkampf look...y el inglés se rigidiza, secuestrado por el tono germánico, "language obscene" que dibuja la figura del padre-hombre-marido cercana a la de Hitler. Pero mientras el otro-masculino es puesto allí, en ese grotesco de "nítido moustache", fascista odiado por los pueblos, la arrasadora disciplina aséptica de la madre figura como ausente, no-dicha, salvo en otros poemas. Ella-la hija-que-habla aparece como un cuerpo cortado o focalizado tan sólo en la cara aplastada por la bota militar (que ahora sabemos doble), y allí, la lengua trabada. La mandíbula (jaw) es ese espacio físico alambrado, ese campo de concentración donde ella es forzada a decir yo por boca del padre (ICH) pero desde la O-mueca de la luna-madre : es esa conjunción la que genera en ella lengua menor, la lengua-como-judía. No es ocioso, entonces, que en "Daddy" jaw aparezca a final de verso y estrofa y haga dibujo con las cuatro apariciones siguientes de Jew (judía : el español nos obliga a definir el género), ocupando también esa posición de final de verso; mientras que en "The moon and the yew tree" las definiciones de la luna-madre acoplan en un mismo verso una rima interna y aliteración aterradoras : "She is bald and wild" ("Ella es calva y salvaje"). La otra imagen doble surge -como ya dijimos- en relación con los habitats de la que habla. En "Daddy", el cuerpo de la hija ha vivido amurado en un zapato negro : “...black shoe/ in which I have lived like a foot" (“...zapato negro/ en el que he vivido como un pie") : el encastre del I (yo) es perfecto, atrapado entre la rima que une los dos sonidos shoe-foot. En "The moon and the yew tree" el lugar es la O-mueca en total desespero de la luna-madre, calva y salvaje : "I live here" ("Yo vivo aquí"), con un tiempo presente aún más asfixiante. En los Diarios se dice:

It is not that I myself do not want to succeed. I do. But I don't need success with the desperation I have felt for it: that is an infusion of fear that successlessness means no approval from mother: and approval, with mother, has been equated for me with love, however true that is. 
WHY DON'T I FEEL SHE LOVES ME? WHAT DO I EXPECT BY “LOVE” FROM HER? WHAT IS THAT I DON'T GET THAT MAKES ME CRY? I think I have always felt she uses me as an extension of herself [...] How, by the way, does mother understand my committing of suicide? As a result of my not writing, no doubt. I felt I couldn't write because she would appropriate it. Is that all? I felt if I didn't write nobody would accept me as a human being. Writing, then, was a substitute of myself: if you don't love me, love my writings \& love me for my writings. It is also much more: a way of ordering and reordering the chaos of experience. (December 27, 1958). ${ }^{13}$

En el final del párrafo, la escritura de Sylvia Plath se afirma en la salida salvadora, y así coincide con Pasolini en su poema "Al Príncipe" (1961) :

Para ser poetas, hay que tener mucho tiempo :

horas y horas de soledad son el único modo

para que se forme algo, que es fuerza, abandono, vicio, libertas, para dar estilo al caos. ${ }^{14}$

Y con Deleuze-Guattari (1991 : 199) :

Lo que define el pensamiento, las tres grandes formas del pensamiento, el arte, la ciencia y la filosofía, es afrontar siempre el caos, estableces un plano, trazar un plano sobre el caos [...] El arte se propone crear un finito que devuelva lo infinito.

Es esa salida al infinito dando forma al caos lo que el poema-Plath propone con maestría. En la cárcel minúscula se traza la línea de fuga. Es en ese doble encierro padre-madre donde surge el otro modo de decir-se, en la lengua menor oprimida y que a la vez resiste. La absoluta y dramática opción del matar o morir, suicida o asesina, resulta fallida ${ }^{15}$; entonces acudir a la menor y salvadora, en el desacato irónico y el delirio asociativo que domina en "Little Fugue". Aunque el "padre mío", de "mentalidad prusiana" ha muerto ya, la mirada retrospectiva ubica la infancia de la niña en tiempos de la Gran Guerra ("Great War"), pero dos estrofas más arriba en la misma posición de final de verso se habló de la Gran Fuga ("Grosse Fugue"). En ese espacio entre una y otra dominaba aquella voz tan poderosa que hasta en el recuerdo se vuelve objeto visible "I see your voice/ black and leafy" ("Veo tu voz/ negra y frondosa ") ${ }^{16} ;$ y se armaba otra imagen del encierro en la repetición de la $r$ en las palabras claves: "A yew hedge of orders,/ Gothic and barbarous, pure German." (“Un cerco de tejos de órdenes/ Góticas y bárbaras, puro Alemán”). Allí está, atemorizada, apenas sobreviviendo, la yo-menor-hija, mientras los demás mueren a su lado. Sólo atina a salvar-se en su impureza, su tono casi de judía, cuando dice : "I am guilty of nothing" ("Soy culpable de nada"), poniendo el peso en esa ecuación contradictoria: guilty-nothing. Pero cuando leemos que el aliento germánico arrasador también le llega a Plath por la otra vía : no sólo en la lengua del padre sino también en la de la madre-abuela de origen austríaco, ese sonido se vuelve agobiante en la construcción, simple y barroca al mismo tiempo, de la nada como posesión o territorio. Esta nadificación repetida nos lleva a ese otro verso clave: "I am myself and it is not enough" ("Soy yo misma y eso no es suficiente"), de "The jailer" ("El carcelero" : en español es obligatorio el género y nos fuerza a poner un masculino, que en inglés no existe), también de 1962. Si en una primera lectura podemos pensar en el hombre-carcelero, la lectura de todo el corpus de poemas de Plath más los Diarios y Letter's Home (traducido al español como Cartas a mi madre), hacen levantar también a la figura de la madre como la del cerrojo, o cómplice en el encarcelamiento. En este sentido leemos el poema "The Rival" ("Rival"), donde otra vez la luna-O vuelve a ser clave :

If the moon smiled, she would resemble you.

You leave the same impression,

of something beautiful, but annihilating. 
Both of you are great light borrowers.

Her O-mouth grieves the world; yours is unaffected,

And your first gift is making stone out of everything. ${ }^{17}$ ("grieves", "apenas" -del verbo apenar-) que provoca dolor y se expande al mundo entero, mientras que el paralelo-hombre-par aporta su dureza en el intercambio con las cosas. En "The jailer" se insiste en el mismo juego aniquilador para la definición de la que habla : se declara un lleno ("I am") que es hueco o vacío ("nothing-not enough"); es decir un lleno vuelto hueco en el desamparo de un no-afecto, o un afecto cuyo efecto es el ser-arrasado :

My enemies are those who care about me most. First: my mother. Her pitiful wish is that I "be happy". Happy! That is indefinable as far as states of being go. Or perhaps you can run it off glibly, as Eddie did, and say it means reconciling the life you lead with the life you wish to lead (often, I think, meaning the reverse). ("Smith College, 1950-1955", p. 35) ${ }^{18}$ diarios, los poemas y las cartas atenaceado por una exigencia férrea de auto-disciplina, y de una serie de demandas de lo que la hija debería ser o hacer, como explicábamos antes. En el párrafo de los Diarios que sigue a continuación, se ve precisamente la posición interna de ese auto-flagelo. En la lista rigurosa de deberes auto-impuestos, el aprendizaje del Alemán (con mayúsculas) ocupaba un lugar destacado y se vuelve emblema de la doble vía disciplinaria padre-madre :

I feel I've cheated myself on languages. I haven't really worked at learning it, and must be tutored in German next year. (27 February 1956) (el subrayado enfático sobre la falta de esmero en el trabajo es de Plath). ${ }^{19}$

\section{En una carta a la madre dice:}

The half year ahead seems like a lifetime, and the half behind an endless hell. Your letters are like glühwein to me. (I must really learn German. I want above all to speak it). (October 12, 1962) (subrayado de Plath). ${ }^{20}$

Por eso, era necesario salir de ese no-lugar. En "Little Fugue" al mismo tiempo que las palabras declaran el encierro en la paradoja del lenguaje, se evoca el negro túnel como posible escape, mientras aparecen la pierna cortada del padre y las salchichas serruchadas en California como cuellos, en un cruce de referencias grotescas que el poema diseña sonora y gráficamente : Great War y Grosse Fugue ${ }^{21}$ : se declara la guerra al carcelero padre-madre ${ }^{22}$, y se planea el escape.

Ahora bien, como ella misma explicitara acerca de su trabajo con el sonido y el sentido de las palabras en las páginas de su Diario, sabemos que el poema de Plath juega rítmicamente con la connotación y el despliegue de sentidos; por eso, la traducción se hace tan ardua, en la tarea de perder lo menos posible de ese volumen sinfónico y significante que es el poema. "Grosse Fuge" nos dice el banco de datos de Internet es una pieza musical compuesta por Beethoven sobre la base de la forma musical "Fuga" inaugurada por Bach, compositor antes de la "Little Fugue". El poema de Plath escribe "Fuge" para la pieza de Beethoven, en el interior del poema, y "Fugue" para la pieza de Bach, cita implícita del título. Sin embargo, acerca de esta diferencia ortográfica se nos dice: "Bach spelled it fuge (note the missing " $u$ ") because he was German, and that's how you spell fugue when you're German". ${ }^{23}$ Pero la palabra provenía, evidentemente, del término italiano "fuga", que dio con igual significado "fuga" en español, ambos provenientes del latín "fugere" (huir). Para el sustantivo "fuga" propone el diccionario 
del español : "evasión, pérdida mental, escape, pérdida de gas". El poema de Plath cita la composición de Grosse Fuge de Beethoven, con la escritura alemana de fuge pero titula el poema mismo como Little Fugue, reenviando a Bach y con la escritura más aceptada para el inglés : una vez más la disputa de las lenguas dominantes y las lenguas menores, las que intentan la fuga, el escape o desvío. A partir de la $5^{\mathrm{a}}$ estrofa, el poema insiste (la fuga como forma musical está basada en la repetición, el contraste y la variación) en destacar sonora y visualmente ciertos finales de versos que sobresalen en el dibujo del texto. Aquellos en los que aparece el exabrupto de las mayúsculas son :

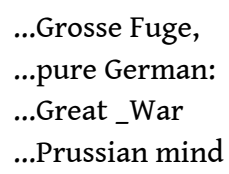

Aquí pisa fuerte, casi con bota militar, la G mayúscula de German, con un juego gráfico similar al de las mayúsculas que propone la poesía de Emily Dickinson. Cuando aparece "my father !" con minúsculas estas palabras forman parte del verso "Such a dark funnel, my father", inmediatamente después de la estrofa que culmina con "the Grosse Fuge". La asociación entre "funnel" (embudo, cuerno que se usa para la aliviar la sordera) y "túnel" se hace tan estrecha que la traductora del Centro Editor de América Latina no vacila en elegir este último sin más explicaciones, aún cuando la palabra aparece en un contexto en el que se habla de la música de Beethoven y de la sordera. El túnel liga la infancia con la bota germana, que ahora sabemos es la lengua doble, padre-madre. El gran túnel negro, subterráneo, surge también como escape de la cárcel de la lengua dominante: un subterfugio, un giro al que se sale por la investigación de sí. Asombrosa la capacidad de la poesía de Plath para pasar de la escena doméstica a la política. La Gran Guerra es la figura de la infancia violentada en la disciplina germánica, que obliga a intentar la pequeña fuga. Grandes escenas montadas en el teatro de las palabras, que vuelven colectiva la experiencia individual del yo arrasado en la privación del afecto y el desamparo de una disciplina sin retaceos. Un cuerpo cortado y una lengua trabada en la voz de las dos figuras parentales Padre-Madre, que nadifican, como en un estado narcótico :

For weeks I can remember nothing at all

(Poem for a Birthday, 1959) ${ }^{24}$

Sin embargo, en el mismo poema se incluye "Dark house" ("Casa negra" o "Casa oscura"), que la que habla construye ("I made it myself", "La hice yo misma"), celda por celda, a modo de laberinto para el escape ; y que en la estrofa final, encuentra la salida hacia la luz del afecto :

Pebble smells, turnipy chambers.

Small nostrils are breathing.

Little humble loves!

Footlings, boneless as a nose,

It is warm and tolerable

In the bowel of the root.

Here's a cuddly mother. ${ }^{25}$

17 Se trata de una auto-construcción defensiva; se alinean celdas de refugio mientras se definen las rutas de la fuga: "I must make more maps" ("Tengo que trazar más mapas"). Las condiciones sanadoras halladas participan en vocabulario y posiciones de otro poema del mismo año 1959 : “The Sleepers" ("Los Durmientes"), en el que la dimensión del sueño aporta su condición salvadora. Como la paciente de "Tulips" ("Tulipanes"), la sin lengua, la no-yo elige fugar-se por esa misma nadidad, entregando su pasado civil a los enfermeros 
y médicos: "I am nobody"26 ("Yo no soy nadie"), "I have no face" ("Yo no tengo rostro"). Cuando los textos de Plath se fugan de la escena del doble secuestro es cuando hallan esa felicidad de estar fuera de la trampa en poemas que se abren a un territorio diferente. ${ }^{27}$ En los Diarios, en cambio, esa fuga es vivida como culpa :

Why am I obsessed with the idea I can justify myself by getting manuscripts published? Is it an escape - an excuse for any social failure - so I can say "No, I don't go out for many extracurricular activities, but I spend a lot of time writing." Or is it an excuse for wanting to be alone and meditate, not having to brave a group of women? (Women in numbers have always disturbed me.) ("Smith College, $1950-1955^{\prime \prime}$, p. 33) ${ }^{28}$

I felt into bed again this morning begging for sleep, withdrawing into the dark, warm, fetid escape from action, from responsibility. No good. ("Smith College, 1950-1955", p. 60) (el subrayado es mío) ${ }^{29}$

***

I wonder at my morbid obsession of daydreams this past month ("Smith College, 1950-1955", p. 75) (subrayado mío) ${ }^{30}$

$$
\text { *** }
$$

If I live at home, I will be alone all summer, unless I seek out neighbors. I will be not earning money, and not really spending money. I will have to be cheerful and constructive, and scheduled my day much harder than if at Harvard. I will learn about shopping and cooking, and try to make Mother's vacation happy and good. That in itself would be worthwhile. I will work two hours a day at shorthand, and brush up my typing. I will write for three or four hours Each Day, and read for the same amount of time from a reading list I draw up carefully, so I won't read hit or miss. ("Smith College, 1950-1955", p. 84) (subrayado mío) ${ }^{31}$

Yet so constantly I am moving, working, acting, that I do not often think "How strange this is...I am competently frying eggs for three children on Sunday morning while the parents sleep. I must learn about these people - try to understand them, put myself in their place." No, instead I am so busy keeping my head above water that I scarcely know who I am, much less than anyone else is. But I must discipline myself. ("July 1950-July 1953", Unabridged Journals, p. 76-77) (subrayado mío) ${ }^{32}$

En esta sucesión de citas resulta interesante observar las resonancias del mapa rítmico de la poesía de Plath que se aloja en los párrafos de sus Diarios: paralelismos y rimas internas, aliteraciones, hacen de los Diarios (como será también con las cartas de Letter's Home) una zona fronteriza entre poesía y prosa, en la que una específica y misma cantidad formal se actualiza. ${ }^{33} \mathrm{Y}$ el trazado rítmico del mapa gira casi obsesivamente sobre las mismas palabras, aunque a veces ocupen posiciones éticas opuestas a la de la poesía (especialmente en los primeros años de los Diarios) : así dark- fetid son aquí atribuidos al escape (escape) o fuga, cuando en "Little Fugue", "Daddy" y "The yew tree" pertenecen a la atmósfera del lenguaje alemán del que se debe huir. Así también el denostado daydream atribuido a una forma de enfermedad (obsession) se opone a los valorados responsabilitydicipline- work- I have to- who am I: justamente las antípodas de la posición sostenida en "The Sleepers" y "Tulips", en los que se desea el bien del dormir liso como el espacio libre, la blancura-nieve del hospital, el soy-nadie-lejos-de-la-vida-social. De este modo, la poesía se asocia con esa otra dimensión del estar- horizontal- tendido que abre la experiencia a territorios nuevos y salvadores, mientras el estar- vertical señala el agobio del deber y la auto-disciplina, que los Diarios muestran como un mandato internalizado en la voz de la hija escritora desde la voz alemana del par madre-padre. 
19 Sin embargo, lo más interesante es que la poesía de Plath -como toda gran poesía- hace estallar la trampa de la clasificación "poesía confesional", en la que muchos han querido encerrarla. Gracias al intenso efecto de cantidad formal más cantidad formal eso que suena como novela familiar-biográfica es arrasado como cárcel y se desborda, y los poemas son, entonces, iluminaciones de una encrucijada cultural, social e histórica, y por ende, colectiva : nos hablan con precisión del estado de nuestra cultura a mediados del siglo XX, con anclajes singulares en la cultura específica de Estados Unidos. ${ }^{34}$

\section{Corolario : un recorrido por el estilo espistolar y las Letter's home}

Pero la obsesión formal microscópica de esta escritura no ha podido borrar en el imaginario de esta sociedad del espectáculo en la que vivimos (Debord), la terrible escena final de Sylvia Plath: la cabeza en el horno, la bandeja de desayuno lista para sus dos pequeños hijos a la espera de la niñera. Una perfecta escena para Hollywood recién aprovechada en Sylvia, estrenada en octubre del 2003 en New York. Esa escena ha borrado durante mucho tiempo (y lo mismo hace el film, como último efecto macabro) la relevancia fundamental de la obra de Plath y el placer que depara leer su fina escritura. Esa era la imagen que ella se propuso dejar para la posteridad : la de una gran escritora, y que su vida paradójicamente pareció sustraerle con la escena trágica del suicidio. En el epistolario Plath exhibe en forma evidente ese legado literario que ella previera con exactitud. En octubre de 1962 le escribe a su madre, ya en el final cuando su vida afectiva parecía derrumbarse :

I am a writer I am a genius of a writer; I have it in me. I am writing the best poems of my life; they will make my name. (October 16, 1962) (¿puntos suspensivos de Aurelia Plath ? $)^{35}$

Consecuente con la imagen de la luna descrita en "The yew tree", la madre Aurelia Plath figura como antologista y editora de estas cartas, publicadas con el título Letter's Home, aunque se trate mayoritariamente de cartas a la madre, de ahí el título que se eligió para la edición en español Cartas a mi madre. ${ }^{36}$ La edición de Aurelia Plath se presenta con una gran cantidad de molestos puntos suspensivos, lagunas en blanco, que cortan la sintaxis y nos escamotean muchas palabras y frases escritas por Plath, y confunden sus posibles blancos con las elipsis armadas por la madre: una 0-mueca que marca el vacío, que nadifica, que vampiriza las palabras de la hija, no sabemos con qué criterios. Pero más allá de todas las implicancias biográficas a las que estas cartas puedan prestarse de buen grado, se ofrecen como una lectura absolutamente feliz y maravillosa. Felicidad de la escritura. A medias entre el libro de memorias, el diario y la novela biográfica, las cartas de Sylvia Plath a su casa desde el exilio elegido (como las de Rimbaud desde África a su madre y hermana) son en modo especial cartas a la madre, quien como una especie de interlocutor privilegiado-ausente y, a la vez presente en la acción de censura y corte de las mismas cartas, nos muestra el registro minucioso y obsesivo de su hija en el intento por sobrevivir y llegar a ser la gran escritora en la que finalmente se convirtió.

Uno podría pensar que tanto los diarios como las cartas de este tipo de escritores grandiosos y obsesivos (Kafka, Virgina Woolf, Katherine Mansfield) son una forma bella y productiva de los "reality shows" que hoy pueblan la televisión local siguiendo la moda de las del primer mundo, con registro también detallado pero sólo de una paupérrima y mezquina mediocridad. En cambio en estas cartas, la escritura se mueve como esa cámara 
que se empeña en registrar minuciosamente cada "falta" al destino de ser un gran escritor/a, la culpa, la pena y la asfixia de no poder escribir, mientras nosotros lectores recibimos testimonios en cada línea de esa gran escritura desenvolviéndose. Encontramos en estas páginas el magnífico e incansable ritmo poético de Sylvia Plath, su partitura flotante anclada también en las cartas, cada vez que se extiende en minuciosas y exquisitas descripciones de paisajes y ambientes diferentes (Massachusetts, Cambridge, Nueva York, Londres, Devon, Marsella o París), en la aguda observación de personas y estilos, en el humor mordaz e hipercrítico, en la autoexigencia aniquiladora que ya leímos en los Diarios. Es que Cartas y Diarios son los dos márgenes desboradados y a veces contrapuestos como en juego de veladuras, que destila el mapa rítmico de Sylvia Plath.

Estas cartas, así como sus diarios y poemas, también podrían considerarse como un precioso "manual" que ninguna mujer debiera obviar. Un "manual" que describe también minuciosamente (esta minucia se alza como uno de los procedimientos o técnicas agudamente manieristas del libro), los obstáculos que una mujer escritora del siglo XX ha debido seguir para luchar y sobrevivir a pesar del aplastante medio masculino, y escindida en un rol que la cultura hace ver como doble y contrapuesto: sostén de la familia y escritora dedicada a su trabajo de escribir. Una exigencia desmesurada de éxito en el cumplimiento de ese doble rol le llegaba desde la pareja padre-madre hasta la mirada del otro/otra, la sociedad y la cultura en que había crecido. Ello resulta en un aniquilador discurso disciplinario encarnado como un bisturí que abre y abre heridas en un cuerpo exhausto frente a la imposible tarea asignada; y que, al mismo tiempo, se empeña en cumplir en toda la línea y en su máxima expresión. Sylvia Plath, como nadie en el siglo XX hemos dicho, ha sabido llevar ese supuesto plano íntimo, familiar y privado a un plano social y cultural donde las figuras "familiares" se pierden en tanto biográficas para alcanzar la dimensión de verdaderas líneas de fuerza sociales y culturales. Como quería Foucault, tan solo un diagrama de fuerzas en lucha, una retícula de micropoder exhibida y desmantelada. Así, del mismo modo que el temor al frío impedía a Rimbaud el regreso a su casa en Francia, para Plath la imposibilidad de enfrentar el fracaso financiero y personal le hacían imposible el regreso a la exigente cultura de "America" (Estados Unidos), que ella identifica con la cara de Aurelia Plath, dos verdaderas A mayúsculas. Escribe a su madre luego de su divorcio, en las últimas cartas antes de su muerte :

I should say right away America is out for me (...) I must make a life my own as fast as I can (...) the flesh has dropped from my bones. But I am a fighter. Money is my only way to fight myself into a new life (...) Also, as you can see I haven't the strength to see you for some time. The horror of what I saw you see last summer is between us and I cannot face you again until I have a new life. (October 9, 1962) (subrayado nuestro) (¿los puntos suspensivos, de Aurelia Plath ?) ${ }^{37}$

I have absolutly no desire ever to return to America (...) I could never afford to live in America. (February 4, 1963) (subrayado nuestro) ${ }^{38}$

De este modo, la barrera de lo que es vivido como un fracaso frente a las exigencias del otro resulta infranqueable : nunca se podrá enfrentar a América-Aurelia-Madre otra vez. Y esta cara, más allá de lo biográfico, delinea los pilares de la cultura norteamericana de la segunda mitad del siglo XX : disciplina, éxito, dinero ; y prevé la crítica interna que el movimiento de contra-cultura realizaría a partir de los años sesenta en Estados Unidos.

Pero otras riquezas depara este libro, que se puede leer también como un atípico libro de misterio o enigma : antes que nada un gran silencio parece dominarlo. Es la obsesión de la escritura de Plath la que dibuja la cara de la luna -en absentia- y nos hace preguntarnos 
qué dirían, por ejemplo, las cartas de la puntillosa Prof. Aurelia Plath, en respuesta a las de su hija, la poeta Sylvia Plath, cómo sería ese discurso que tantas veces vemos sobrevolar las palabras de la hija amenazante y casi aterrador. Pequeñas señales, pistas simpre mínimas pero excesivas hace crecer a lo largo de estas páginas, esa figura que aparece como temible para la que firma estas cartas, al mismo tiempo que se le rinde pleitesía y se le declara constante amor. Ese sesgo dicotómico, que imposibilita la salida salvadora, y que recorre toda la escritura de Plath (ser "vertical" u "horizontal", "puritana" o "diabólica", "virginal-inocente" o "fea-con pelos", etc), aparece aquí implacable en esos vislumbres que surgen en medio del ferviente amor declarado sin cesar hacia la madre y la ansiedad expresada una y otra vez por recibir sus cartas, y al mismo tiempo temer sus reacciones. Cuando sucede un episodio de aborto, o la separación con Ted Hughes, sólo se expresa el dolor frente a la segura decepción de la madre y la imposibilidad de ver su cara otra vez; y cuando ésta pretende darle dinero mensual, en cambio, o intenta dirigirle la escritura, surgen los irritados comentarios :

Will you please, for goodness sake, stop bothering poor Winifred Davies!...She is busier than either you or I and is helping me as much as she can and knows and sees my situation much better than you can...I want no monthly dole, especially not from you. You can help me best by saving your money for your own retirement... I am even enjoying my rather frustrating (culturally and humanly) exile now. I am doing a poem a morning, great things [...]. Don't talk to me about the world needing cheerful stuff! What the person out of Belsen -physical or psychological - wants is nobody saying the birdies still go tweet-tweet [...] Let the Ladies' Home Journal blither about those. (October 21, 1962) (el subrayado enfático es de Plath, ¿los puntos suspensisvos de Aurelia Plath ? ${ }^{39}$

Mínimas acotaciones a lo largo de innumerables declaraciones de amor a la madre, que se levantan como grietas en una fachada, o rajaduras en un jarrón de preciosa porcelana por donde un espeso vapor parece destilarse hacia afuera. El mismo desfasaje se percibe en el contraste de los comentarios ordenadores de la Sra. Plath, como aquel en el que nos anticipa que el período de Cambridge fue el más placentero y pletórico para su hija, mientras ésta declara páginas más adelante, como único comentario sobre el mismo período : “ fue el año más esclavizante y duro de nuestras vidas”. Torsión y desfasaje que se pueden leer en los párrafos eliminados, con el autoritario criterio de que "no serían de interés para el lector", o el desesperado intento por corregir el efecto de las últimas cartas y proteger así la figura de Ted Hughes con esta "advertencia" : "Son cartas desesperadas, (....). Pero debo pedir al lector que recuerden las circunstancias en que fueron escritas y que también tengan en cuenta que sólo representan una cara de una situación extremadamente compleja". He aquí el mismo triángulo asfixiante que atrapa el poema "The Rival", escrito en 1961, y que propone el siempre punzante problema de la atribución de género para la traducción : ¿"La Rival” ? Preferimos "Rival”, sin artículo, como decir : sin cabeza, sin sujeto, una vez más una línea de fuerza que el poema pone en la luz de la luna y en la forma de 0 que ofrece como un grito. La misma fuerza que en otros poemas se pone del lado de la maternidad ("Edge") en conjunción con la muerte, como para ponernos a repensar las teorías de Kristeva acerca de la melancolía femenina. En el texto de Sylvia Plath : campo de concentración y exterminio por la Lengua Paterna, muerte lunar y vampírica por la Lengua Materna. Sin salida salvo por la obsesión de la forma.

27 Por fortuna y a pesar de todo, el talento de Sylvia Plath pudo sobrevivir y sobrepasar la escena del suicidio y todas las trampas post-mortem a las que su escritura fue expuesta. Con la misma fuerza con la que escribiera la última carta-texto ocho días antes de morir, 
una tarea tan desmesurada como las trabas que tuvo en su camino ha sabido guiar su escritura: la intensa búsqueda de una lengua, desbordada de las lenguas maternopaternas, en punto de fuga hacia una densa y estilizada cantidad formal.

\section{BIBLIOGRAFÍA}

\section{Bibliografía}

Adorno, Theodor. “Discurso sobre lírica y sociedad”. Notas de literatura. Barcelona : Ariel, 1962.

Adorno, Theodor. La teoría estética. Buenos Aires : Hyspamérica, 1984 [1970]

Badiou, Alain. Pequeño manual de inestética. Buenos Aires : Prometeo, 2009 [1998]

Benjamin, Walter. "La tarea del traductor”. Angelus Novus. Barcelona : Edhasa, 1971 [1923].

Benjamin, Walter. Libro de los pasajes. Madrid : Akal, 2005.

Bergson, Henry. El pensamiento y lo moviente. Buenos Aires : La pléyade, 1970 [1934]

Deleuze, Gilles. Qué es la filosofía. Barcelona : Anagrama, 1993.

Deleuze, Gilles. La inmanencia : una vida. En : Philosophie, n. 47, 1 de septiembre de 1995 (Se encuentra en Internet traducido al español por Consuelo Pabón).

Deleuze, Gilles y Guattari, Felix. Kafka. Por una literatura menor. México : Ediciones Era, 1978 [1975]

Derrida, Jacques. El monolingüismo del otro. Buenos Aires : Manantial, 1997.

Eco, Umberto. Dire la stessa cosa. Esperienze di traduzione. Milan : Bompiani, 2003.

Freud, Sigmund. "Lo ominoso" (“Das Unheimlich”). Obras completas, t. XVII. Buenos Aires : Amorrortu, 1999 [1919]

Freud, Sigmund. "Más allá del principio del placer", Obras completas, t. XVIII. Buenos Aires : Amorrortu, 1999 [1920]

Klein, Mélanie. Envidia y gratitud. Barcelona : Ediciones Paidós Ibérica, 1988 [1957]

Muschietti, Delfina. "Leer y traducir : restos y robos melancólicos" (2004). En : Filología, XXXIIIXXXIV (número doble), en prensa.

Muschietti, Delfina. “Traducción de poesía : forma, repetición y fantasma en el estudio comparado de traducciones de Emily Dickinson (Silvina Ocampo, Amelia Rosselli)". En : Orbis Tertius, Universidad Nacional de La Plata. Versión online (2006)

Muschietti, Delfina et al. "Poesía y Traducción : una nueva Filología”. Traducir poesía : la tarea de repetir en otra lengua. Buenos Aires : La Marca, en prensa. (2013)

Olson, Charles. "Projective Verse". Human Universe and other essays. New York : Grove Press, 1967 [1965]

Rosselli, Amelia. Impromptu. Traducción de Delfina Muschietti. New York : Pen Press, 2004 [1980] 
Tinianov, Iuri. El problema de la lengua poética. Buenos Aires : Siglo XXI, 1970 [1923]

\section{Obras de Sylvia Plath}

Plath, Sylvia. Collected Poems (1956-1963). Edited with an Introduction of Ted Hugues. London : Faber and Faber, 1990 (First published 1981)

Plath, Sylvia. The Bell Jar (1963). New York : Harper and Row, 1971 (First published London, Heineman)

Plath, Sylvia. The Journals of Sylvia Plath. Foreword by Ted Hugues. Ted Hugues Consulting Editor. New York : 1992 (First published 1982)

Plath, Sylvia. The Unabridged Journals of Sylvia Plath, (1950-1992). Transcribed from the original manuscripts at Smith College, edited by Karen Kukil. New York : Anchor Books, 2000.

Plath, Sylvia. Letter's Home of Sylvia Plath. Correspondence 1950-1953. Selected and Edited with Commentary by Aurelia Schober Plath. New York : Harper \& Row Publishers, 1975.

\section{NOTAS}

1. El famoso poema J288 de Dickinson (que luego citará Plath en "Tulips") lo dice bien claro en tonalidad irónica, jugando con la respuesta de Ulises al Polifemo : "I am Nobody/ Who are you ?" ("Yo soy Nadie / Quién eres Tú"). Nobody es también un no-cuerpo, o un cuerpo definido por la negación. (La traducción es nuestra)

2. "Pongamos dos afirmaciones atrevidas : No hay nada sentimental acerca de una máquina, y: Un poema es una pequeña (o larga) máquina hecha con palabras. Cuando digo que no hay nada sentimental en un poema, quiero decir que en él no puede haber ninguna parte que sobre.

La prosa puede transportar una carga de imprecisas materias como un barco. Pero la poesía es una máquina que procede recortándose en una perfecta economía. Como en todas las máquinas, el movimiento es intrínseco, ondulante, físico más que de tipo literario." (Introducción de Williams a The Wedge. Selected Essays of William Carlos Williams. NY: New Directions, 1969, p. 256. La traducción y el subrayado son nuestros ).

3. "Cada palabra puede ser analizada - desde el punto de vista de los matices, valores, frialdad, calidez, asonancias y disonancias de vocales y consonantes. Técnicamente, pienso que la apariencia visual y el sonido de las palabras, tomadas aisladamente, funciona en modo muy parecido a la mecánica de la música...o del color y textura en la pintura. De todos modos, siendo una neófita en esos campos, sólo puedo suponer y experimentar." (Todas las traducciones de textos de Sylvia Plath nos pertenecen).

4. Ver el poema "Tulips" y la lectura que se hace de éste en relación con J. L. Ortiz y P.P. Pasolini en el capítulo 10 de "Poesía y Traducción : una nueva Filología" en Muschietti et al (2013, en prensa).

5. Austria tiene al alemán como lengua oficial, y la lengua local, el austro-bávaro. es una variante del alto alemán, pero está a su vez sitiada por el alemán oficial standard. Los apellidos de Sylvia son Plath -Schober.

6. En "The Swarm" : "Somebody is shooting at something in our town" ("Alguien está disparando a algo en nuestra ciudad"), se dice como si se tratara de un suceso que se repite una y otra vez, siempre hay allí alguien disparando un arma. Ted Hughes, el marido poeta, dice acerca de Plath en el poema "Fever" : "a little bit crazy for America/ And its medicine cupboard." ("Un poco loca para América/ y su armario de medicinas”), y marca así el extravío de Plath con respecto al statu quo. En los Diarios también se verifican numerosas entradas en las que el ser-poeta - tanto para 
ella como para Hugues - aparece cuestionado por la madre en relación a una inseguridad económica que caerá como espada de Damocles sobre las espaldas de Plath durante toda su vida. En "Hospital Notes" (Boston 1958-1959), por ejemplo, se dice: "How can I be happy when I did something so dangerous as to follow my own heart and mind regardless of her advice [the mother's] and Mary Ellen Chase's disapproval and the pragmatic American world's cold eye: but what does he do for a living? He lives, people. That's what he does." (p.271) (“Cómo puedo ser feliz si he hecho algo tan peligroso como seguir mi propio corazón y mente, sin considerar su consejo [el de su madre] ni la desaprobación de Mary Ellen Chase y el pragmático frío ojo del mundo de América : pero qué hace él para vivir ? Él vive, gente. Eso es lo que él hace." NT: "what does he do for a living?" significa "¿de qué trabaja él, de qué vive?", pero si lo traducimos así perdemos el juego de palabras que hace Plath con la respuesta: "Él vive, gente. Eso es lo que él hace". Por eso preferimos usar un modo algo menos corriente en español "¿qué hace él para vivir?").

7. El guión, fuera de la norma en español aquí, sirve para dar la conexión fuerte entre sangre y fría , que en inglés funciona como adjetivo de mother, todo unido en cold-blooded. La poesía de Plath abunda en estos adjetivos compuestos con guión entremedio.

8. "Leo Duelo y Melancolia de Freud después de que Ted se fuera a la biblioteca. Una casi exacta descripción de mis sentimientos y razones para el suicidio : un impulso asesino transferido desde mi madre hacia mi interior : la metáfora del "vampiro" que usa Freud, "drenando el ego" : ése es exactamente el sentimiento que tengo cuando voy a mi escritura : el ahogo de Madre."

9. Para la definición de "lengua menor", ver Deleuze-Guattari 1975.

10. En su novela The Bell Jar, aparecida poco antes de la muerte de Plath, a comienzos de 1963, la narradora dice : "cuando estás casada y tienes hijos es como si te hubieran hecho un lavado de cerebro y vas dando vueltas como un necio, como el esclavo de un estado totalitario privado" (subrayado nuestro). Obviamente, la imposibilidad de vivir la familia por la vía del amor, viene dado por la doble negación del afecto padre-madre : en ese desamparo, la tierra se vuelve tierra arrasada y cruzada por la Envidia (en términos de M.Klein), a la espera de algún otro efectoafecto salvador, que construya la fuerza opuesta de la Gratitud.

11. Tal como es descrito por Plath en la edición de sus Diarios no censurados por Ted Hughes, al relatar el comienzo del matrimonio de sus padres : "Se casaron en Reno. El se volvió un enfermo el mismo momento en que el sacerdote les dijo que podían besarse. Enfermo y enfermante. Ella se dio cuenta de que él era un bruto, no podía amarlo y no lo hizo. Se forzaba a permanecer bajo la ducha disfrutando del agua caliente sobre su cuerpo, porque lo odiaba intensamente. Él no iría a ver a un doctor, no creería en Dios y vivaba a Hitler en privado." En: The unabridged Journals of Sylvia Plath, edited by Karen V.Kukil. NY: Anchor Books, 2000.

12. Inevitable pensar en el "y me velas la voz", o el "no tendré palabras, no tendré deseos..." ("Oye", 1919) de Alfonsina, la auto aniquilación cuando la violencia autoritaria se ejerce sobre un cuerpo singular.

13. "No es que yo no quiera ser exitosa. Lo quiero. Pero no necesito el éxito con la desesperación que he sentido hasta ahora al buscarlo : esto es una infusión del miedo que proviene de que la falta-de-éxito significa no aprobación de mi madre: y la aprobación, con mi madre, ha sido equiparada por mí con el amor, no importa cuán verdadero sea esto.

POR QUÉ NO SIENTO QUE ELLA ME QUIERE ? QUÉ ESPERO DE ESE SU “AMOR” ? QUÉ ES LO QUE NO OBTENGO, QUE ME HACE LLORAR? Creo que siempre he sentido que ella me usa como una extensión de sí misma [...] Cómo, en ese sentido, entiende madre mi intento de suicidio ? Como resultado de mi no estar escribiendo, sin dudas. Yo sentía que no podía escribir porque ella se apropiaría de ello. Es eso todo ? Sentía que si yo no escribía nadie me aceptaría como ser humano. Escribir, entonces, era un sustituto de mí misma : si no me amas, ama mis escritos \& ámame por mis escritos. Es también mucho más : un modo de ordenar y reordenar el caos de la experiencia." 
14. En La religión de mi tiempo (1961), según mi traducción en la antología : Pier Paolo Pasolini. La mejor juventud. Buenos Aires : La Marca, 1999.

15. "Daddy, I have had to kill you"... "At twenty I tried to die" en el mismo poema "Daddy".

16. Una vez más, imposible evitar la relación con la voz dominante del otro en la poesía de A.Storni, o la posición del padre, el muerto, en la de A.Pizarnik.

17. "Si la luna sonriera, ella se parecería a ti. / Dejan la misma impresión / De algo hermoso pero aniquilador. / Ambos, grandes robadores de luz. / La O-boca de ella apena el mundo, la tuya es suelta, / Y tu gran don es volver piedra a toda cosa." (Inventamos la palabra "robadores" para "borrowers" para seguir con el efecto vampírico declarada por Plath en los Diarios, y porque la semejanza sonora acerca también los sentidos).

18. "Mis enemigos son los que más se preocupan por mí. Primero : mi madre. Su patético deseo es que yo "sea feliz". Feliz! Eso es tan indefinible, tanto cuantos estados del ser haya. o quizás podamos darlo vuelta, engañosamente, como Eddie dice, y decir que significa reconciliar la vida que llevas con la vida que deseas llevar (a menudo, pienso, significa lo opuesto)."

19. "Siento que me he engañado a mí misma en cuanto a las lenguas. No he trabajado realmente en el aprendizaje, y deberé tener tutoría en Alemán el año próximo.” (NT : Dejamos Alemán con mayúsculas para respetar la importancia de la palabra en la obra de Plath, y por las asociaciones con el nombre de la madre Aurelia.)

20. "La mitad del año hacia adelante parece toda una vida, y la mitad hacia atrás un infierno sin fin. Tus cartas son como glühwein para mí. (Debo realmente aprender Alemán. Quiero sobre todo aprender a hablarlo)" (NT: "Glühwein" ["vino caliente"] : en alemán en el original, por eso conservamos la misma incrustación extranjera en la traducción al español. Conservamos también la mayúscula para el nombre de la lengua, dada la importancia que adquiere en toda la obra y porque en ella aparece siempre como German: aunque de acuerdo con la norma de la granática inglesa, en la escritura de Plath esa $G$ mayúscula adquiere un tono y una textura especiales)

21. Grosse Fuge: Esta denominación podría referir- quizás de manera irónica- a un episodio sucedido en 1944, cuando un grupo de prisioneros de guerra británicos se fugan de un campo alemán a partir de la construcción de un largo túnel subterráneo. El episodio fue filmado después con gran éxito en el film The Great Escape, en 1963, año del suicidio de Plath. Sin embargo, la fórmula "Grosse Fuge" remite a una pieza musical de Beethoven, como hemos ya señalado.

22. Una situación muy similar con ambas figuras parentales aparece en el largo poema "Impromptu" de la poeta ítalo-inglesa Amelia Rosselli. No es casual que Rosselli haya traducido a Dickinson y a Plath.

23. The Fugue, en http://www.incompetech.com/music/fugue.html

24. "Por semanas no puedo recordar nada en absoluto" (Poema para un cumpleaños).

25. "Olor a guijarros, cámaras de nabo / Pequeños orificios respiran/ Pequeño humilde amor !/ Simple, sin huesos como una nariz,/ Es cálido y tolerable/ En las entrañas de la raíz./ Aquí es una adorable madre."

26. Esta, a su vez, es una cita del poema J288 de Emily Dickinson ("I am nobody : who are You ?"), como señalamos al comienzo. Dickinson fue precursora del humor corrosivo contra el rebaño de la identidad civil, como pocos años después lo hiciera Alfonsina Storni en "La loba", de 1915.

27. "Child" ("Niño"), "I am vertical but I'd rather to be horizontal" ("Soy vertical pero preferiría ser horizontal”), "Morning Song” (“Canción de mañana”), "Sleepers" ("Durmientes”), y el mismo "Tulips".

28. " Por qué estoy obsesionada con la idea de que me puedo justificar si logro publicar mis manuscritos? Es un escape - una excusa para cualquier posible fracaso social, así puedo decir "No, no hago muchas actividades extracurriculares, pero invierto mucho tiempo escribiendo" ? o es una excusa para mi deseo de estar sola y meditar sola, sin tener que enfrentarme con un grupo de mujeres ? (Las mujeres en número siempre me han perturbado.)" 
29. “Caí en la cama otra vez esta mañana rogando por dormir, arrastrada hacia el oscuro, cálido, fétido escape de la acción, de la responsabilidad. Nada bien."

30. "Me pregunto sobre mi mórbida obsesión de soñar-despierta del mes pasado."

31. "Si vivo en casa estaré sola todo el verano, a menos que salga a buscar vecinos. No estaré ganando dinero, y no estaré realmente gastando dinero. Tengo que ser alegre y constructiva, y organizar mi día mucho más duramente que en Harvard. Aprenderé a hace compras y a cocinar, y trataré de hacer felices las vacaciones de Madre. Eso en sí mismo ya vale la pena. Trabajaré dos horas al día practicando taquigrafía, y refrescando mi mecanografía. Escribiré durante tres o cuatro horas Cada Día, y leeré la misma cantidad de tiempo de una lista de lectura que armaré cuidadosamente, así no leeré al acaso ni perderé nada."

32. "Sin embargo, estoy constantemente moviéndome, trabajando, actuando, tanto que no pienso con frecuencia "Qué extraño es esto...Estoy competentemente friendo huevos para tres niños en la mañana del domingo mientras los padres duermen. Tengo que aprender más sobre esta gente tratar de entenderlos, ponerme en su lugar." No, en cambio, estoy tan ocupada manteniendo la cabeza afuera del agua que escasamente sé quién soy, mucho menos que cualquier otro. Pero tengo que disciplinarme a mí misma."

33. En la terminología de Jacques Derrida (1997).

34. En este sentido, son muy interesantes las entradas de los Diarios sobre la guerra de Corea, la ejecución de los Rosenberg en la silla eléctrica en la novela The bell jar, que se asocia además con el tratamiento de electroshock recibido luego del primer intento de suicidio.

35. "Soy una escritora ... Soy un genio como escritora; lo tengo en mí. Estoy escribiendo los mejores poemas de mi vida ; ellos me harán un nombre."

36. Cartas a mi madre. Traducción de Ana María Moix. Barcelona : Mondadori, 2001.

37. "Debo decir rápidamente que América está descartada para mí. (...) Debo hacerme una vida propia tan pronto como pueda (...) la carne se me ha caído de los huesos. Pero soy una luchadora. El dinero es mi única manera de luchar para hacerme de una nueva vida. (...) También, como podrás ver no tengo fuerzas como para verte por un tiempo. El horror que vi tú has visto el pasado verano está en medio de nosotras y no puedo mirarte a la cara otra vez hasta que no tenga una nueva vida." (En la traducción se pierde la mayúscula de Money, que la falta de artículos del inglés hace posible luego del punto y aparte. Otra mayúscula realmente importante para el mundo familiar de Plath.)

38. "No tengo en absoluto ningún deseo de regresar nunca a América. (...) Nunca podría costearme vivir en América."

39. "Querrías por favor, por misericordia, dejar de molestar a la pobre Winifred Davies ?...Ella está más ocupada que tú o yo, y está ayudando tanto como puede, y ve mi situación y la conoce mucho mejor de lo que puedes tú... No quiero ninguna suma mensual, especialemente viniendo de ti. Me ayudarías más si ahorraras tu dinero para tu propio retiro...

Yo estoy hasta disfrutando ahora de mi frustrante exilio (cultural y humano). Escribo un poema por día, grandes cosas [...] No me digas que el mundo necesita cosas alegres ! Lo último que una persona salida de Belsen quiere oír es alguien hablando de que los pajaritos todavía vuelan y pían [...] Deja al Ladies' Home Journal parlotear sobre eso." (Se refiere, claro está, al campo de concentración nazi situado en la ciudad de Belsen. Todo ese horror alemán estaba muy cerca de Plath en el principio de los '60). 


\section{RESÚMENES}

Siguiendo a Iuri Tinianov y a Walter Benjamín en constelación teórica, podemos decir que, al traducir un poema, perseguimos un fantasma : el "eco" de una respiración, el armado de una construcción rítmica, que hemos llamado mapa rítmico o partitura flotante, en conexión con un plano de inmanencia, o plataforma flotante; y que en esta forma radica la especificad del poema. Concebimos el poema como una máquina rítmica, que delega en su motor de repetición una condición anómala o extranjera, que nos lleva a una dimensión alejada de la cotidianidad y de los ejes tempo-espaciales que persigue la prosa. En la poesía de Sylvia Plath la conexión con el plano de inmanencia se grafica en la posición del cuerpo horizontal, el estar tendido o suspendido, que se dispone a la escritura; mientras la posición del cuerpo vertical refiere al estar atrapado en las redes de la identidad civil y el imaginario cultural. Plath, como Pasolini y Deleuze, piensa la escritura del poema como una tensión para dar forma al caos. Se trata de una forma que, alejándose de la ley del sentido, se liga técnicamente con la materia sonora y el color de las palabras segmentadas en pura materia en el plano de inmanencia, para luego regresar en la composición de la partitura-poema, que va del detalle al infinito. En cartas y diarios, Plath retoma el mapa rítmico del poema, practicando inversiones y antonimias que enriquecen el volumen sinfónico de su obra.

Suivant Iuri Tinianov et Walter Benjamin, que nous adoptons comme constellation théorique, on peut dire que lorsque nous traduisons un poème, nous poursuivons un fantôme : l'« écho » d'un souffle, le montage d'une construction rythmique, que nous avons appelé carte rythmique ou partition flottante, en contact avec un plan immanent ou plateforme flottante; et c'est dans cette forme que réside la spécificité du poème. Nous pensons le poème comme une machine rythmique qui loge dans la répétition sa nature étrange ou atypique, nous amenant vers une dimension éloignée du quotidien et des axes de temps et d'espace caractéristiques de la prose. Dans la poésie de Sylvia Plath la connexion avec le plan immanent se dessine dans la position horizontale du corps, qui se trouve allongé ou suspendu, prêt à l'écriture, tandis que la position verticale fait référence aux rets de l'identité civile et de l'imaginaire culturel. Plath, de même que Pasolini et Deleuze, pense l'écriture du poème comme une tension destinée à donner forme au chaos. Il s'agit d'une forme qui, s'éloignant de la loi du sens, est techniquement reliée à la matière sonore et à la couleur des mots dans le plan immanent, et qui revient dans la composition du poèmepartition, lequel, à partir du détail, ouvre sur l'infini. Dans ses lettres et journaux, Plath reprend la carte rythmique du poème avec des inversions et des antonymies qui enrichissent la portée symphonique de son œuvre.

Following Iuri Tinianov and Walter Benjamin works as a theoretical constellation, we can say that in translating a poem we seek a phantasm: the "echo" of a breathing, the composition of a rhythmical tissue, that we called rhythmical map or floating score, connected to a plan of immanence or floating score, and that is the specific feature of the poem. We conceive the poem as a rhythmical machine that holds in its repetition motor an atypical condition which leads us to another dimension, detached from daily time, from temporal-spatial axes used in prose. In Sylvia Plath works, the connection with a plan of immanence is drawn by the position of a horizontal body, suspended and lying down, ready to write; while the opposite position, the vertical body, refers to a 
body trapped into the civil identity and collective imaginary. Plath, like Pasolini and Deleuze, thinks about the poem writing as a tension to give form to the chaos. This is a form detached from the law of meaning that technically relies on the materiality of sounds and colors in words, launched from the immanence plan to return in the composition of the score-poem that brings us the infinite inside the detail. Plath takes the rhythmical map of the poem again into her letters and diary, with inversions and oppositions that enrich the symphonic volume of her work.

\section{ÍNDICE}

Mots-clés: Poésie, carte rythmique, partition flottante, plan immanent, Sylvia Plath

Keywords: Poetry, rhythmical map, floating score, plan of immanence

Palabras claves: Poesía, mapa rítmico, partitura flotante, plano de inmanencia

AUTOR

DELFINA MUSCHIETTI

Universidad de Buenos Aires

delfinarten@gmail.com 